\title{
Effect of Recycled Ceramic Waste Content on the Properties of Unsaturated Polyester Resin
}

\author{
Mohamed Farsane ${ }^{1, *}$, Abdellah Anouar ${ }^{2}$, Souad Chah ${ }^{1}$ andMiloudi Bouzziri ${ }^{1}$ \\ 1Laboratory of Physico - Chemistry of Processes and Materials (PCPM). Faculty of Science and Technology of \\ Settat, University Hassan 1st, BP 577, Settat 26000, Morocco; abdellah.anouar@ uhp.ac.ma (A.A) ; \\ souad.chah@uhp.ac.ma (S.C); miloudi.bouzziri@uhp.ac.ma (M.B). \\ ${ }^{2}$ Laboratory of Applied Chemistry and Environment, Faculty of Science and Technology of Settat, University \\ Hassan 1st, BP 577, Settat 26000, Morocco \\ * Correspondence: m.farsane@uhp.ac.m; Tel.: 00212661430391
}

\begin{abstract}
In this study, the properties of unsaturated polyester resin were studied in the presence of recycled ceramic waste particles. Herein, composites were created that contained $28.5-50 \mathrm{wt} \%$ porcelain particles (particle size $<180 \mu \mathrm{m}$ ). High filler contents increased the gel time and decreased the exotherm temperature of unsaturated polyester resin during curing. The obtained results showed that physical parameters, such as the resin density and porosity, increased as the filler content increased. In addition, the X-ray diffraction results indicated that the produced samples were a combination of ceramic waste particles and unsaturated polyester resin, resulting in semi crystalline structure. The results showed that the maximum water absorption at $40^{\circ} \mathrm{C}$ increased from 0.97 to $1.5 \%$ as the filler content increased from 28.5 to $50 \mathrm{wt} \%$; in this process, the materials experienced a color change but did not lose mechanical performance. Finally, the samples were characterized by thermogravimetric analysis (TGA) to study the effect of porcelain powder on the thermal degradation of the resin. The TGA scans were analyzed with the Friedman method. The results indicated that the samples with porcelain powder exhibited substantially better thermal stability than unsaturated polyester resin.
\end{abstract}

Keywords: ceramic waste particles; unsaturated polyester resin; X-ray diffraction; water absorption; thermal degradation; curing process

\section{Introduction}

A composite is a structural material that consists of two or more combined constituents that are combined at a macroscopic level and are not soluble in each other. One constituent is called the reinforcing phase, which is embedded in the matrix. The reinforcing phase may be in the form of fibers, particles, or flakes, where as the matrix is generally continuous.

Ceramic products are essential construction materials used in most buildings. Some commonly manufactured ceramics include wall tiles, floor tiles, sanitary ware, household ceramics, and technical ceramics. These products are made from clay as a raw material and transformed into a durable material through heat treatment. Esposito et al. [1] noted that porcelain stoneware is made via sintering with a maximum temperature ranging between 1210 and $1215^{\circ} \mathrm{C}$, which produces a dense material containing a high amount of glassy phase embedded with residual quartz and crystallized mullite. Vinila et al. [2]indicated that ceramic products can withstand very high temperatures ranging from $1000^{\circ} \mathrm{C}$ to $1600^{\circ} \mathrm{C}$.

It has been recognized that ceramic ware and, consequently, their waste can be divided into groups according to their nature and characteristics. Therefore, in each category, the fired ceramic waste is classified according to the corresponding production process [3,4].

Because ceramic waste, which is classified as non biodegradable, constitutes a significant proportion of the total production in the ceramic industry, recycling ceramic waste is a major problem. However, the possibility of recycling this waste needs to be carefully evaluated based not 
only on the processes of origin but also on the other industrial activities related to the waste. In this regard, interesting opportunities are offered by the traditional ceramics industry. From an industrial perspective, it is also very important to define both the economic benefits and the quality of the products. Although the reutilization of ceramic wastes is ongoing, the amount of waste being reused is still negligible. Important investigations have already been carried out on this topic[4,5].

The construction industry, as the end user of nearly all ceramic materials, is well poised to solve this environmental problem, for which construction is partially responsible. The nature of the construction industry, especially the concrete industry, is such that ceramic waste can be used safely with no need for dramatic changes in production and application processes. This reuse will avoid the cost of disposing ceramic waste in a landfill and reduce the use of raw materials and natural resources, thereby saving energy and protecting the environment. According to some authors, the best way for the construction industry to become more sustainable is by using waste from other industries as building materials.

It is well established that the chemical composition of fired ceramic products is not significantly different from that of the raw materials used to make the products; only the mineralogical composition is modified when these materials are heated [3]. Silica and alumina are the most significant oxides present in ceramic pastes $[3,6]$. In addition, due to the high firing temperature, ceramic products are characterized by very high density, as noted in the literature (water absorption $<0.5 \%)$ [7].

The use of inorganic fillers in the formulations of unsaturated polyester resin (UPR)-based composite materials has been widely reported; these filler scan reduce the cost and change specific properties of cured materials [8]. Kubota[9] studied the effect of calcium carbonate on the curing behavior of polyesters. They reported that as the particulate content increased, the curing started at a lower temperature, and the total heat generated during the curing reaction decreased.

The properties of a composite may vary because of changes in the reinforcement or matrix microstructures, the loading conditions, and the surrounding environment, such as heat $[10,11]$ and moisture [12-14]. Generally, composite materials that are applied in construction are subjected to different temperatures. Due to the potential exposure to fires, the composite materials should initially resist high temperatures to allow time to take preventive measures. Hence, an extensive study on the thermal aging of composites is required. With regard to thermal decomposition kinetics, an alternative approach to kinetic analysis is to use model-free methods that allow for evaluating the Arrhenius parameters without choosing the reaction model. Isoconversional methods are the most popular methods based on the use of multiple heating programs [15].

For polymer materials, aging tests are one of the most prevalent methods to estimate the service life of product. These aging tests of polymer materials are performed either under actual operating conditions or under conditions that simulate an artificial accelerated environment.

To test the sensitivity of the polymer materials to aging, it would be necessary to use test methods that reflect particular conditions in which the finished products are used.

To determine the effect of aging on the properties of polymeric materials, the changes in the properties of the tested samples are assessed during the exposure period, and then the altered properties are compared to the properties of the untreated samples.

Nevertheless, previous research in this area is scarce and does not evaluate the effect of ceramic waste on the formulation of UPR, which is a vital issue. This is the scope of this study.

\section{Materials and Methods}

\subsection{Material Preparation}

Ceramic sanitary wares, such as basins, toilets, bathrooms, and sinks, were collected from public landfills in Settat, Morocco. These devices were broken with a hammer and crushed in a crusher to obtain a granular material with particles smaller than $4 \mathrm{~mm}$ in diameter. The ceramic waste was then dry milled in alumina media (30\% alumina balls, $30 \%$ ceramic waste, and $40 \%$ air) 
for $30 \mathrm{~min}$ to obtain a ceramic powder. Ceramic powders with a particle size $<180 \mu \mathrm{m}$ were chosen for this investigation.

UPR with a cobalt octoate accelerator $(0.5 \%)$ and a methyl ethyl ketone peroxide (MEKP, $2 \%$ ) catalyst were chosen for this investigation. The specific gravity of the resin was 1.13 , the viscosity at $25^{\circ} \mathrm{C}$ was $7.5-9$ poise, the acid value was $20-30 \mathrm{mgKOH} / \mathrm{g}$, and the styrene content was $34 \%$.

The UPR was well mixed with appropriate quantities of porcelain powder (PP) for 10 min using a paste mixer. Then, the catalyst and accelerator were added into the mix. The system was thoroughly mixed for an additional $10 \mathrm{~min}$. Once the mixture was homogeneous, it was poured into a mold and placed under vacuum to prevent the formation of bubbles in the open air for 72 hours before demolding. The prepared samples were designated A1, A2, A3, and A4, for which the percentage of PP used, was $0,28.5,41$, and $50 \mathrm{wt} \%$, respectively.

\subsection{Experimental Method}

Diffraction data were collected at room temperature on a Phillips D $5000(\theta-\theta)$ diffractometeroperated at $40 \mathrm{kV}$ and $40 \mathrm{~mA}$ with Bragg-Brentano geometry and $\mathrm{Cu} \mathrm{K} \alpha$ radiation $(\alpha=$ $1.54056 \AA$ ). The patterns were scanned with a step size of $0.01^{\circ}(2 \theta)$ in the $2 \theta$ range of $15-80^{\circ}$.

The density, or more precisely, the volumetric mass density, of a substance is its mass per unit volume; density is typically denoted $\varrho$.

The density values (@) were calculated with the following equation:

$$
\rho=\rho_{0}\left(\frac{A}{A-B}\right)
$$

Where $\mathrm{Q}_{0}$ is the fluid density (water), $\mathrm{A}$ is the sample weight in air, and B is the sample weight in liquid.

Based on ISO 1172 and ASTM D 2734[16], the void volume fraction can be calculated as follows:

$$
\mathrm{V}_{\mathrm{v}}=1-\rho_{\mathrm{c}}\left(\frac{\mathrm{W}_{\mathrm{m}}}{\rho_{\mathrm{m}}}+\frac{\mathrm{w}_{\mathrm{f}}}{\rho_{\mathrm{f}}}\right)
$$

Where $\varrho$ and $\mathrm{W}$ are the experimentally determined density and weight fraction, respectively, and the subscripts $\mathrm{m}, \mathrm{f}$, and $\mathrm{c}$ denote the matrix, fiber, and composite, respectively.

The samples $(20 \mathrm{~mm} \times 10 \mathrm{~mm} \times 2 \mathrm{~mm})$ were cut from the bulk sample and kept at standard temperature for the water absorption test. Then, the samples were immersed in a static water bath at $40^{\circ} \mathrm{C}$ for different time periods. After certain periods of time, the samples were removed from the bath, dried with tissue paper and then weighed.

The relative weight change during water absorption was determined as follows:

$$
\Delta \mathrm{m}=\frac{\mathrm{M}_{\mathrm{t}}-\mathrm{M}_{0}}{\mathrm{M}_{0}} * 100
$$

Where $\Delta \mathrm{m}(\mathrm{t})$ is the moisture uptake and $\mathrm{m}_{\mathrm{t}}$ and $\mathrm{m} 0$ are the mass of the specimen before and during aging, respectively.

During this accelerated aging, both the hardness and color changes in the materials were assessed.

A hardness test was chosen to characterize the evolution of the material resistance as a function of immersion time in the water. At least five specimens of each type were created and tested to obtain an average hardness and avoid possible errors obtained because of the no uniform distribution of the fillers. Rockwell hardness tests were carried out at room temperature in accordance with ASTM D 785 [17].

Thermogravimetric analysis (TGA) was carried out with a thermal analyzer(Labsys TM Evo TGA-DTA $1600^{\circ} \mathrm{C}$, TA Instruments) at different heating rates $\left(10,15\right.$ and $\left.20^{\circ} \mathrm{C} \cdot \mathrm{min}^{-1}\right)$ from 25 to $650^{\circ} \mathrm{C}$ in an argon atmosphere; this analysis was numerically controlled. A $20 \mathrm{mg}$ sample was placed in a platinum pan for each test. Prior to the experiment, the instrument was calibrated to ensure precise temperature and weight readings. 


\section{Results and Discussion}

\subsection{Curing Process Results}

The curing reaction is a very important stage when processing UPR to produce a composite product. To achieve good product quality, the curing reaction should occur in a controllable manner [18]. The reactivity of the mixes containing PP (obtained from ceramic waste) and UPR was evaluated to determine the viability of using these alternative raw materials as fillers in the production of new materials. Additionally, the gel time, time to peak, and exothermic temperature were evaluated. Hereafter, the results are obtained, and their interpretations are presented.

The results show that adding PP to the resin resulted in a delay in the curing reaction. The effect of the PP on the delay of the cure reaction followed the order A4 $>\mathrm{A} 3>\mathrm{A} 2>\mathrm{A} 1$, and the numerical results are detailed in Table 1.With regard to the peak exothermic temperature, following observations were made:

Table1. Effect of recycled ceramic waste content on the physical properties (density (@) and porosity $\left.\left(\mathrm{V}_{\mathrm{v}}\right)\right)$, curing characteristics (gel time $\left(\mathrm{t}_{\mathrm{gel}}\right)$ and time to peak $\left.\left(\mathrm{t}_{\mathrm{max}}\right)\right)$ and water saturation $\left(\mathrm{M}_{\infty}\right)$.

\begin{tabular}{|c|c|c|c|c|}
\hline Sample & $\mathrm{Q}\left(\mathrm{g} / \mathrm{cm}^{3}\right)$ & $\begin{array}{c}\mathrm{V}_{\mathrm{v}}(\%) \\
\mathrm{M}_{\infty}(\%)\end{array}$ & $\operatorname{tgel}(\min )$ & $t_{\max }(\min )$ \\
\hline A1 & 1.18 & ---- & 06.30 & 11.00 \\
\hline & & 0.74 & & \\
\hline A2 & 1.32 & $\begin{array}{l}3.77 \\
0.97\end{array}$ & 09.50 & 15.45 \\
\hline A3 & 1.35 & $\begin{array}{l}5.50 \\
1.10\end{array}$ & 10.15 & 16.30 \\
\hline A4 & 1.43 & $\begin{array}{l}6.77 \\
1.50\end{array}$ & 13.00 & 18.30 \\
\hline
\end{tabular}

The presence of PP lowers the maximum temperature reached during the cure cycle. Increasing the filler content reduces the total amount of resin, thereby decreasing the amount of heat generated per unit volume of the reacting mixture. The degree of temperature reduction appears to be dependent on the filler content, as shown in Figure 1. This finding reinforces the idea that the reduction in temperature is due primarily to a dilution effect from the filler. Kubota [9] reported that the presence of a high filler content in the cure system increased both the thermal conductivity and the viscosity of the resin; however, a high filler content also reduced the concentration of reactive double bonds per unit volume. It was noted that while the first two factors enhanced the cure reactions, the last factor had an unfavorable effect on curing. According to their observations, as the filler content increased, curing initiated at a lower temperature, whereas the total heat of curing decreased.

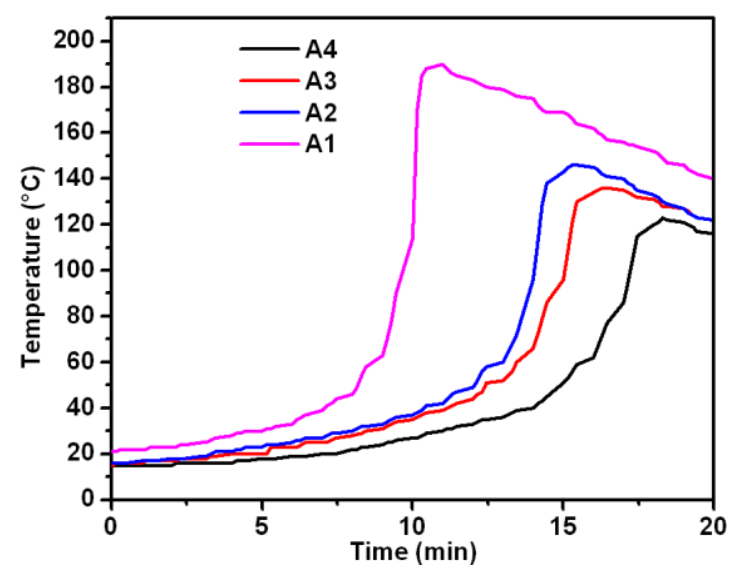

Figure 1.Temperature vs. timeusing $2 \mathrm{wt} \%$ MEKP and $0.5 \mathrm{wt} \%$ Co solution and varying concentrations of $\mathrm{PP}$ at room temperature. 
Table 1 depicts an increase in gel time when the PP content increases. The increase in gel time in the presence of PP can be attributed to the retardation of the crosslinkage of the UPR and the absorption of the heat generated in the exotherm reaction. Rheological measurements carried out by Simitzis et al.[8] showed that inorganic fillers(talc and quartz) lead to an increase in the gel time, thereby delaying the crosslinking of UPR. They reported that the formed microgels cannot closely connect because they are impeded by the presence of the PP; this phenomenon retards the transition stage and the macrogelation.

\subsection{Density and Porosity Results}

The results of the density test are shown in Table 1 . The density of the samples increased continuously with increasing PP content; this phenomenon occurs because the density of the PP is higher than that of the matrix.

Knowledge of void content is desirable for estimating the quality of products. It is well known that the void content in a material may significantly affect some of its mechanical properties. The test results of porosity are summarized in Table 1.The void content clearly increases as the PP content increases because the liquid phase cannot effectively wet and react with the solid particles [7]; this limitation explains the increased porosity in the A4 sample, which has the highest PP content.

\subsection{X-Ray Diffraction}

The chemical structure and crystallinity of the samples were examined via X- ray diffraction (XRD), and the graph is depicted in Figure 2. The XRD patterns of the composites show both amorphous and crystalline peaks. The amorphous phase originates from UPR, where as the crystalline peaks originate from the PP. UPR gives a halo peak at $18.0^{\circ}$, which suggests the amorphous nature of the resin. The crystalline peaks represent the presence of PP in the composite. These crystalline peaks did not appear in the UPR, which showed only an amorphous halo peak. The intensity of the PP crystalline peaks gradually increased with increasing PP concentration. The XRD pattern suggests that the composites were composed of resin and different concentrations of PP.

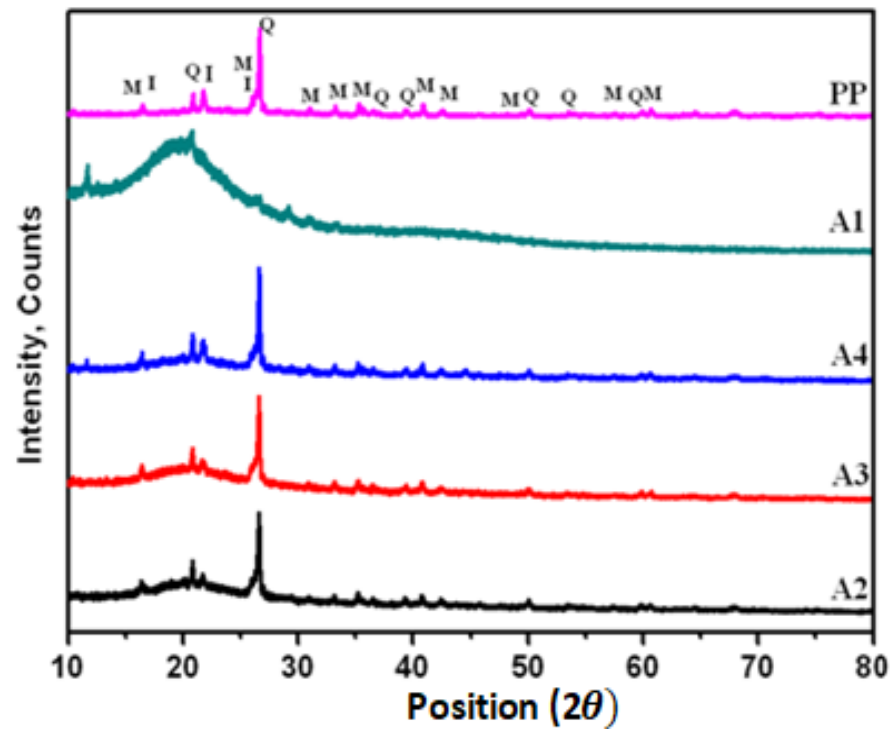

Figure 2. Typicalpowder XRD patterns of resin, PP and samples A1-A4 (quartz (Q), mullite (M), and minor constituent (I)).

The crystalline phases identified in all the samples (A2, A3 and A4) cured at ambient temperature and in the PP obtained from ceramic waste $\left(\mathrm{SiO}_{2}\right)$, which is the residual mineral for the original raw materials. The secondary phases of mullite were formed during firing, and a minor constituent with the chemical formula $\mathrm{C}_{28} \mathrm{H}_{26} \mathrm{~N}_{2} \mathrm{O}_{3} \mathrm{Si}_{2}$ was also detected.

These results confirm the formation of news materials with PP and UPR. 


\subsection{Thermal Degradation}

The above mentioned thermal stabilities were evaluated using TGA at three heating rates (10, 15 , and $\left.20^{\circ} \mathrm{Cmin}^{-1}\right)$. The obtained results are shown in Figures 3 and 4, which represent the mass loss and change $\beta \mathrm{d} \alpha / \mathrm{dT}$ as a function of temperature, respectively. These figures show that both materials exhibit two steps of degradation between $130^{\circ} \mathrm{C}$ and $400^{\circ} \mathrm{C}$. The mass curves were shifted to high-temperature regions as the heating rate increased.
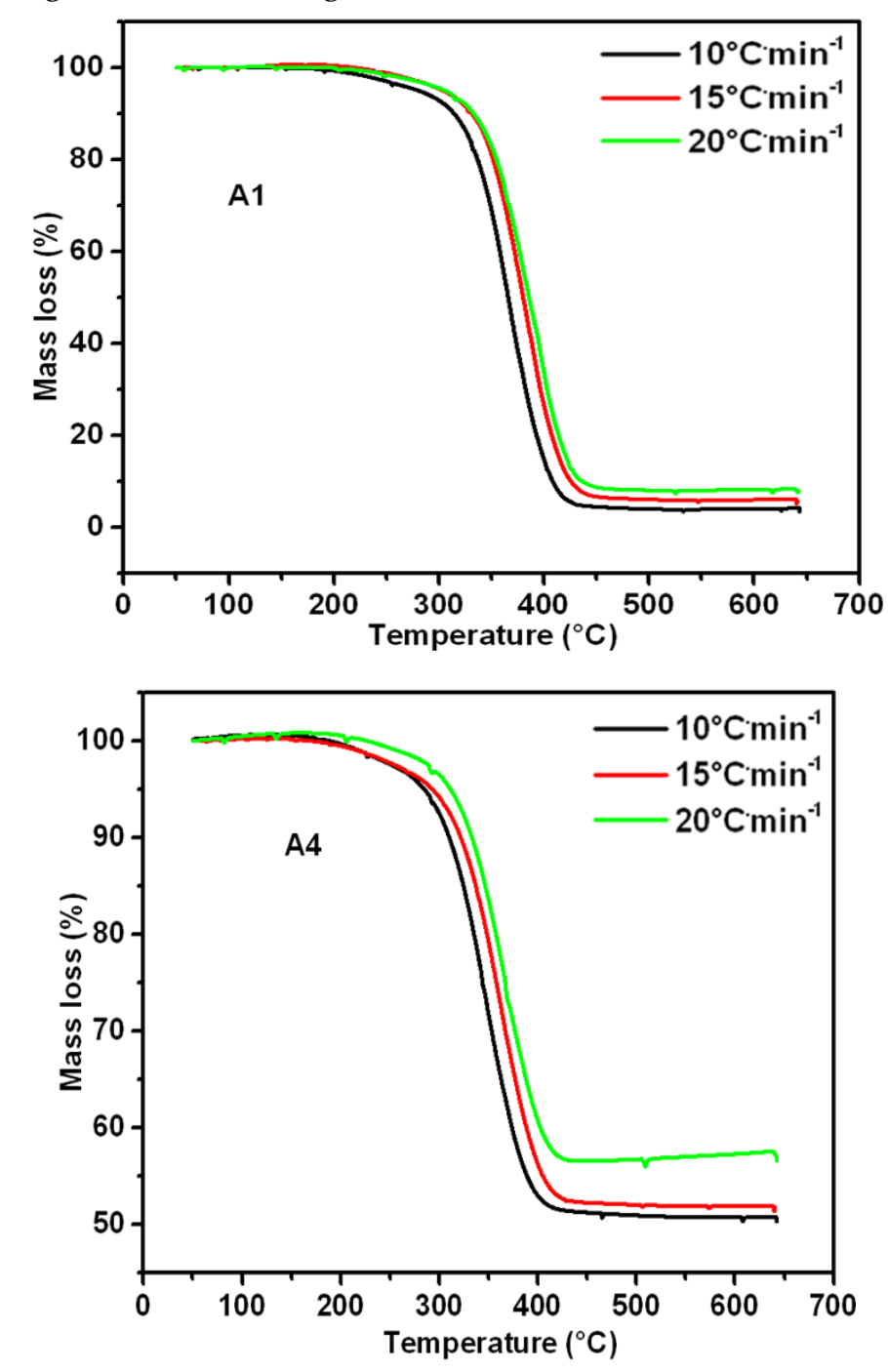

Figure 3. TGA curves for $\mathrm{A} 1$ and $\mathrm{A} 4$ at different heating rates $\left(10,15\right.$ and $\left.20^{\circ} \mathrm{C} \cdot \mathrm{min}^{-1}\right)$. 

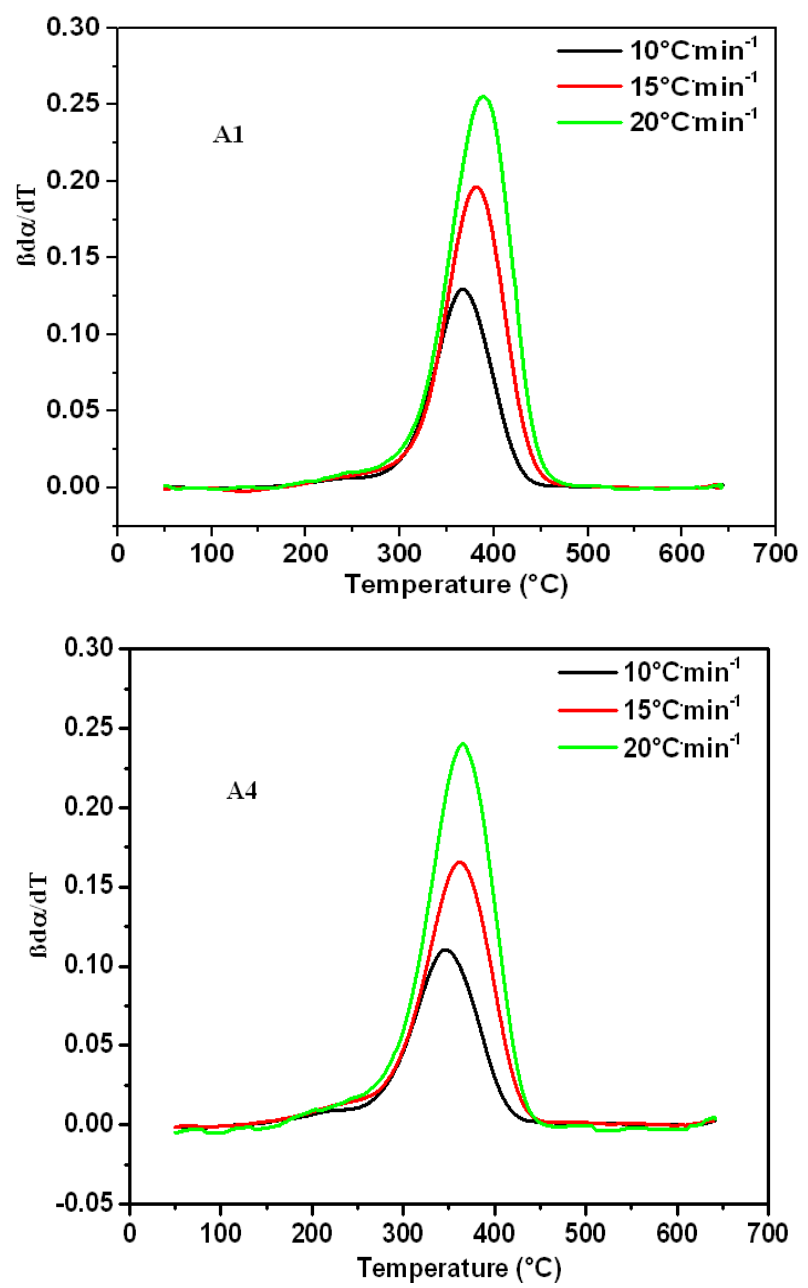

Figure 4. Variation in $\beta \mathrm{d} \alpha / \mathrm{dt}$ as a function of temperature for $\mathrm{A} 1$ and $\mathrm{A} 4$ at differentheating rates (10, 15 and $\left.20^{\circ} \mathrm{C} \cdot \mathrm{min}^{-1}\right)$.

From the TGA measurements, the char yield of the unfilled UPR was found to be $6 \%$. In contrast, the char yield of the UPR with $50 \mathrm{wt} \% \mathrm{PP}$ content is in the range of $50-55 \%$. Van Krevelen[19] reported that the char yield is directly correlated to the potential of flame retardation. Therefore, the findings suggest that adding PP to our new composite markedly increases its flame resistance. Increased char formation can also limit the production of combustible gases, decrease the exothermicity of the pyrolysis reaction, and inhibit the thermal conductivity of the burning materials [20].

\subsubsection{Kinetic Analysis of TGA Data}

The Friedman method [21] utilizes the following logarithmic differential expression:

$$
\ln \left(\frac{\mathrm{d} \alpha}{\mathrm{dt}}\right)=\ln \left(\beta \frac{\mathrm{d} \alpha}{\mathrm{dT}}\right)=\ln \left(\operatorname{Af}(\alpha)-\frac{\mathrm{E}}{\mathrm{RT}}\right.
$$

where the extent of conversion is defined as $\alpha=\left(\mathrm{m}_{0}-\mathrm{m}_{\mathrm{t}} / \mathrm{m}_{0}-\mathrm{m}_{\mathrm{f}}\right)$, in which $\mathrm{m}_{0}$ is the initial mass, $\mathrm{m}_{\mathrm{t}}$ is the mass at time $t$, and $m f$ is the final mass; $\beta$ is the heating rate; $E$ is the activation energy; $A$ is the pre-exponential factor; $\mathrm{R}$ is the gas constant; and $\mathrm{f}(\alpha)$ is the differential expression of kinetic model function.

E represents the minimum energy required to transform a substance from a steady state to an activated state; therefore, the activation energy is a good indicator regarding how easily a material can be decomposed. 
The kinetic parameters were calculated in accordance with ICTAC recommendations [22].

To determine the kinetic parameters for thermal degradation, we removed 10 " $\alpha$ " values from the samples at different heating rates and read the corresponding temperature from the original data in Figure 4.

A mathematical model (i.e., the Friedman method) was used to evaluate the kinetic parameters of the thermal degradation process. The responses of $\ln (\beta \mathrm{d} \alpha / \mathrm{dT})$ vs. $1 / \mathrm{T}$ for the first and second stage in the thermal degradation process of the composites are plotted in Figure 5.
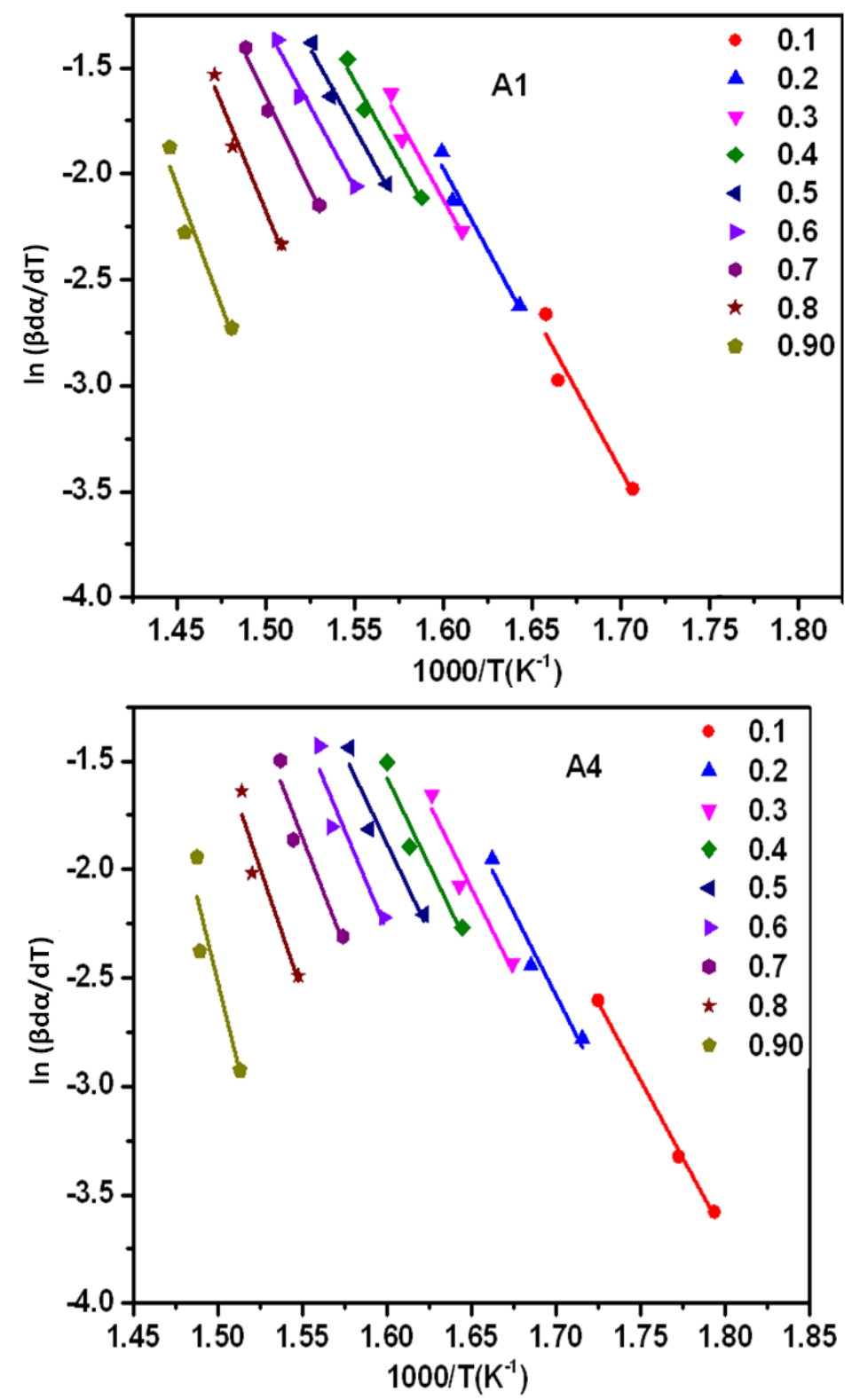

Figure 5. Results from the Friedman method for A1 and A4 at various fixed conversion degrees.

The results obtained from the Friedman isoconversional method suggest that the correlation of the regression lines is very good; the correlation coefficient varies between 0.86 and 0.99 , which shows that the Friedman isoconversional method is appropriate.

To understand the mechanism of thermal degradation, the variation in activation energy as a function of conversion degree for the first and second steps is shown in Figure 6. The figure shows that there was a slight reduction in activation energy for the first step of the degradation process after the incorporation of the PP filler. The lowest E values were observed in the first step of the thermal degradation process for all composites. This phenomenon occurs due to the lower energy required to remove volatile compounds and low-molecular weight (soft component) materials 
present in the UPR. Higher E values were observed in the second step degradation process because higher energies are required for scission.

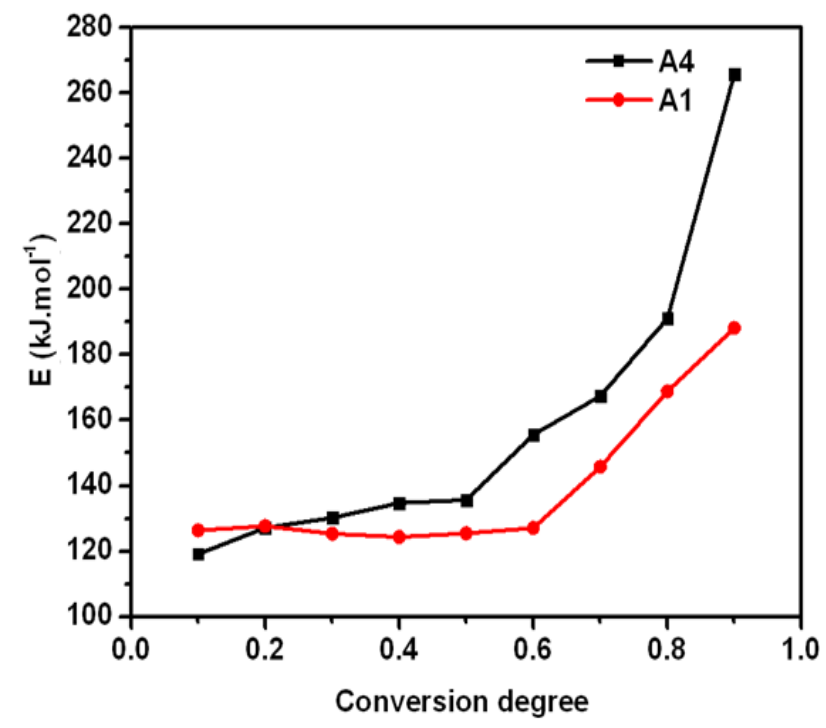

Figure 6. Dependence of the activation energy (E) on the extent of conversion $(\alpha)$.

For UPR, the initial value of E of approximately $126 \mathrm{~kJ} \cdot \mathrm{mol}^{-1}$ at $\alpha=0.10$ and remained constant between 0.1 and 0.6. Afterwards, a significant change occurred, and the activation energy increased from 128 to $190 \mathrm{~kJ} \cdot \mathrm{mol}^{-1}$ at $\alpha=0.9$. Regarding the composites, the initial value of $\mathrm{E}$ of approximately $118 \mathrm{~kJ} \cdot \mathrm{mol}^{-1}$ at $\alpha=0.10$ and remained constant between 0.1 and 0.55 . Afterwards, a significant increase occurred, and the activation energy increased from 130 to $270 \mathrm{~kJ} \cdot \mathrm{mol}^{-1} \mathrm{at} \alpha=0.9$.

Figure 6 shows the apparent activation energy versus conversion obtained by the Friedman kinetic methodology. However, the E profile obtained indicates that the decomposition mechanism is a function of the conversion degree.

Baudry et al.[23] used the Ozawa method to calculate the kinetic parameters for different phases of degradation. They reported that the low-value E typically corresponds to the depolymerization of styrene, which constitutes the micronodules formed in the gelation process. They also indicated that the value of $\mathrm{E}$ in the intermediary degradation phase, which is equal to 170 $\mathrm{kJ} \cdot \mathrm{mol}^{-1}$, could be associated with the proper polyester network. The values with $\mathrm{E}>200 \mathrm{~kJ} \cdot \mathrm{mol}^{-1} \mathrm{can}$ be associated with random scission reactions that lead to the formation of low-molecular weight products.

It is difficult to make comparisons between these results on single polymers and those found in similar studies carried out on the same UPR due to the different operating conditions adopted (e.g., carrier gas, flow rate, and heating rate), the method used for kinetic computations, and the various characteristics of the polymers, such as additives, structure and molecular weight composition.

All these remarkable differences may be responsible for the wide range of $E$ values reported in the literature. For example, Mortaigne et al.[24] used the invariant kinetic parameter method to investigate the degradation of unsaturated polyesters. They found significantly different $\mathrm{E}$ values for the degradation of two different samples of UPR (118 and $\left.138 \mathrm{~kJ} \cdot \mathrm{mol}^{-1}\right)$ due to their different average molecular weights. In any case, the average E values calculated for the degradation of UPR by the Friedman method in this study fall within the wide range reported in the literature, and the agreement is better with those values determined via isoconversional methods.

Similar results were reported by Tibiletti et al.[25], who calculated activation energy through the invariant method of Lyon. The obtained results indicate that the $\mathrm{E}$ changed with respect to the conversion degree, where in $\mathrm{E}$ was $50,100,133 \ldots 206$ at conversion degrees of 5, 5, $30 \ldots 98 \%$, respectively. 


\subsection{Water Absorption Results}

The experiments show that the percentage weight increased as a function of the square root of time at $40^{\circ} \mathrm{C}[26,27]$.

Figure 7 shows the moisture increase vs. the square root of time, in which the relation was linear in the first stage until gradually reaching equilibrium (i.e., Fickian diffusion). Figure 7 shows that the filler contents have substantial effects on the moisture content that a sample can absorb.

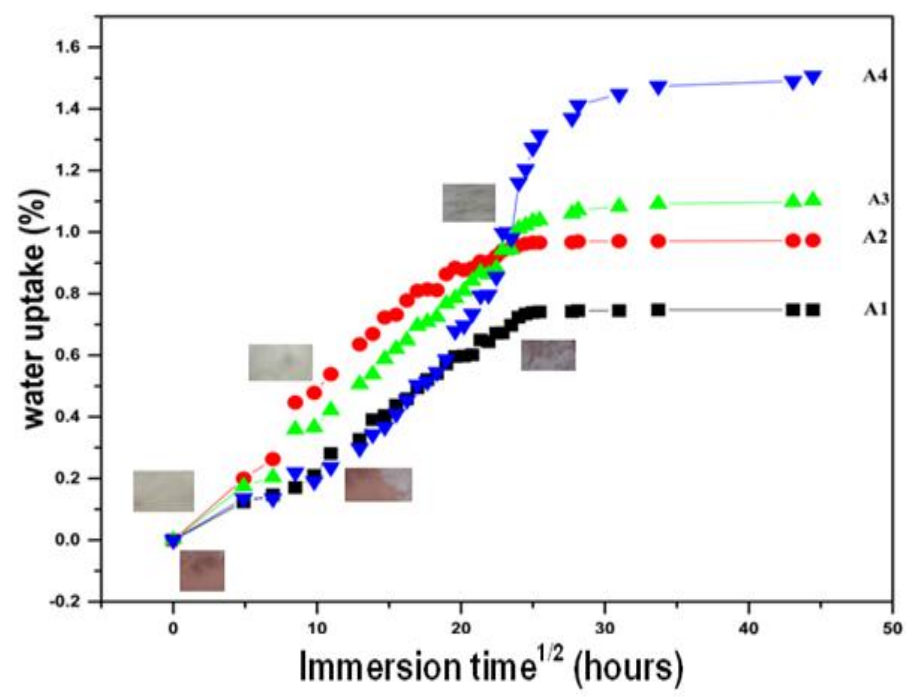

Figure 7.Weight gain in $\mathrm{A} 1, \mathrm{~A} 2, \mathrm{~A} 3$ and $\mathrm{A} 4$ at $40^{\circ} \mathrm{C}$.

Prolonged water immersion may finally cause A1, A2, A3, and A4 to become saturated at $40^{\circ} \mathrm{C}$, and the water absorbed at saturation is proportional to the voids present in the materials (Table 1). A similar finding was reported in the literature[28].

The air-filled voids incorporated in the composite resin during the manual handling of the material may lead to inhibition zones with unpolymerized materials, which may result in higher water absorption [29]. In addition, these voids may be filled with water, thereby increasing the sample weight. The rate of water absorption also depends on the accessibility of water to the composite resin material [30]. In this case, water molecules first enter the open space produced by microvoids formed by cavities and cracks in the matrix. In addition, tiny droplets of water may diffuse inside the interface due to capillary action, which may increase the weight of the composites. During prolonged immersion of the samples in water, the hydrophilic group of the polyester resin is attracted, and chemical reactions occur.

The samples were conditioned at $40^{\circ} \mathrm{C}$ and tested at different time durations to determine the corresponding changes in color and hardness.

The material color and its consistency changed during the immersion period. In particular, the inset in Figure 7 shows three photographs of both A1 and A4 samples, which were taken after 0, 10, and 25 days of immersion in water at $40^{\circ} \mathrm{C}$. The yellow starting color of $\mathrm{A} 1$ ( 0 days) transformed into a progressively darker orange (10 days). The yellow transparent starting color of A1 and A4 (10 days) transformed into a progressively darker yellow-brown color (after 25 days). Both materials lost their starting transparency, becoming opaque and whitened, especially after a long aging time (25 days).

The optical color variations that occurred during the accelerated aging of A1 and A4 suggested that physical and chemical changes occurred in the UPR. The material structures were modified during water immersion because the water present in the polymeric network reacted with the material degrading it by means of hydrolytic reactions and/or by the leaching of small molecules (monomers or oligomers).

It is well known that ester groups present in both resins easily react with water. The chemical modification could be due to the diffusion of water molecules throughout the polymeric chains [31]. 
The average hardness values of A1 and A4 after production and after aging at a temperature of $40^{\circ} \mathrm{C}$ are shown in Table 2.

Table 2. Change in hardness as a function of water immersion time.

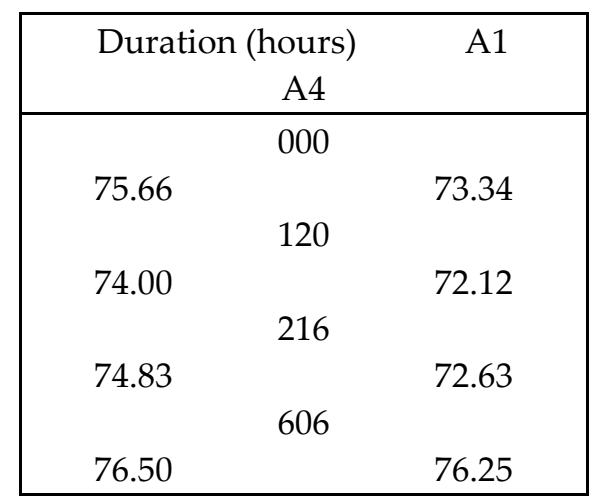

Table 2 shows a slight variation in hardness after aging at $40^{\circ} \mathrm{C}$ for 120,216 , and 606 hours. The variation in hardness is in the range of 1-3 HR, which is negligible.

Slightly decreased values of hardness ( 1 to 2 HR) were measured at A1 and A4 after 120 and 216 hours of aging. In contrast, slightly increased hardness (1 HR) was observed in A1 after 606 hours of aging under the same conditions. Table 2 shows that the average value of the hardness in composite A4 exhibited the highest variance after 606 hours of aging at $40^{\circ} \mathrm{C}$, wherein the hardness was slightly increased (3 HR).

In a previous study, Visco et al. [26] investigated the effect of water absorption on the hardness of UPR. In particular, they determined that the hardness values of UPR changed due to both cure reaction completion and plasticization/degradation from the adsorbed water.

\section{Conclusion}

Within the limitation of the scope of this investigation, the following conclusions are drawn:

The progressive addition of ceramic particles slows the curing process of UPR and decreases the temperature of this transformation.

The increase in the PP content of UPR quantitatively and qualitatively affects the different properties studied.

Author Contributions M.F, S.C, A.A and M.B wrote the manuscript. All authors contributed to revise the sections of the manuscript, read and approved the submitted version.

Funding: “This research received no external funding"

Acknowledgments: The author would like to thank Professors M. M. Bouzziri and M. A. Anouar, who gave many helpful comments and suggestions during the course of this work.

Conflicts of Interest: The authors declare no conflicts of interest. 


\section{References}

1. Esposito, L.; Tucci, A.; Naldi, D. The reliability of polished porcelain stoneware tiles. J. Eur. Ceram. Soc. 2005, 25, 1487-1498; DOI:10.1016/j.jeurceramsoc.2004.05.030.

2. Vinila, V.; Jacob, R.; Mony, A.; Nair, H.; Issac, S.; Rajan, S.; Nair, A.; Satheesh, D.; Isac, J. X-Ray diffraction analysis of nano crystalline ceramic PbBaTiO3. Cryst. Struct. Theory Appl. 2014, 3, 57-65; DOI:10.4236/csta.2014.33007.

3. Pacheco-Torgal, F.; Jalali, S. Reusing ceramic wastes in concrete. Constr. Build. Mater. 2010, 24, 832-838; DOI:10.1016/j.conbuildmat.2009.10.023.

4. Halicka, A.; Ogrodnik, P.; Zegardlo, B. Using ceramic sanitary ware waste as concrete aggregate. Constr. Build. Mater. 2013, 48, 295-305; DOI:10.1016/j.conbuildmat.2013.06.063.

5. Puertas, F.; García-Díaz, I.; Barba, A.; Gazulla, M.F.; Palacios, M.; Gómez, M.P.; Martínez-Ramírez, S. Ceramic wastes as alternative raw materials for Portland cement clinker production. Cem. Concr. Compos. 2008, 30, 798-805; DOI:10.1016/j.cemconcomp.2008.06.003.

6. Rasteiro, M.G.; Gassman, T.; Santos, R.; Antunes, E. Crystalline phase characterization of glass-ceramic glazes. Ceram. Int. 2007, 33, 345-354; DOI:10.1016/j.ceramint.2005.10.002.

7. Tucci, A.; Esposito, L.; Rastelli, E.; Palmonari, C.; Rambaldi, E. Use of soda-lime scrap-glass as a fluxing agent in a porcelain stoneware tile mix. J. Eur. Ceram. Soc. 2004, 24, 83-92; DOI:10.1016/S0955-2219(03)00121-3.

8. Simitzis, J.; Stamboulis, A.; Tsoros, D.; Martakis, N. Kinetics of curing of unsaturated polyesters in the presence of organic and inorganic fillers. Polym. Int. 1997, 43, 380-384; DOI:10.1002/(SICI)1097-0126(199708)43:4<380::AID-PI816>3.0.CO;2-3.

9. Kubota, H. Curing of highly reactive polyester resin under pressure: Kinetic studies by differential scanning calorimetry. J. Appl. Polym. Sci. 1975, 19, 2279-2297; DOI:10.1002/app.1975.070190819.

10. Engindeniz, M.; Zureick, A.-H. Deflection response of glass fiber-reinforced pultruded components in hot weather climates. J. Compos. Constr. 2008, 12, 355-363; DOI:10.1061/(ASCE)1090-0268(2008)12:3(355).

11. Wang, Y.; Meng, J.; Zhao, Q.; Qi, S. Accelerated ageing tests for evaluations of a durability performance of glass-fiber reinforcement polyester composites. J. Mater. Sci. Technol. 2010, 26, 572-576; DOI:10.1016/S1005-0302(10)60087-4.

12. Zafar, A.; Bertocco, F.; Schjødt-Thomsen, J.; Rauhe, J.C. Investigation of the long term effects of moisture on carbon fibre and epoxy matrix composites. Compos. Sci. Technol. 2012, 72, 656-666; DOI:10.1016/j.compscitech.2012.01.010.

13. Aniskevich, K.; Aniskevich, A.; Arnautov, A.; Jansons, J. Mechanical properties of pultruded glass fiber-reinforced plastic after moistening. Compos. Struct. 2012, 94, 2914-2919; DOI:10.1016/j.compstruct.2012.04.030.

14. Jiang, X.; Kolstein, H.; Bijlaard, F.S.K. Moisture diffusion in glass-fiber-reinforced polymer composite bridge under hot/wet environment. Compos. Part B Eng. 2013, 45, 407-416; DOI:10.1016/j.compositesb.2012.04.067.

15. Vyazovkin, S. Sergey Vyazovkin. Handb. Therm. Anal. Calorim. 2008, 5, 503-538;DOI:10.1016/S1573-4374(08)80016-7.

16. ASTM-D2734-94. Standard Test Methods for Void Content of Reinforced Plastics 1; ASTM International: West Conshohocken, PA, 2003.

17. ASTM D785-03. Standard Test Method for Rockwell Hardness of Plastics and Electrical Insulating Materials; ASTM International: West Conshohocken, PA, 2003.

18. Vafayan, M.; Beheshty, M.H.; Nasiri, H. A kinetic model for the low temperature curing of an unsaturated polyester resin with single and dual initiators. Polym. Polym. Compos. 2007, 15, 180-190; DOI:10.1177/096739110701500302.

19. van Krevelen, D.W. Some basic aspects of flame resistance of polymeric materials. Polymer 1975, 16, 615-620; DOI:10.1016/0032-3861(75)90157-3.

20. Liepins, R.; Pearce, E.M. Chemistry and toxicity of flame retardants for plastics. Environ. Health Perspect. 1976, 17, 55-63; DOI:10.2307/3428609.

21. Friedman, H.L. Kinetics of thermal degradation of char-forming plastics from thermogravimetry. Application to a phenolic plastic. J. Polym. Sci. Part C Polym. Symp. 1964, 6, 183-195; DOI:10.1002/polc.5070060121. 
22. Vyazovkin, S.; Burnham, A.K.; Criado, J.M.; Pérez-Maqueda, L.A.; Popescu, C.; Sbirrazzuoli, N. ICTAC kinetics committee recommendations for performing kinetic computations on thermal analysis data. Thermochim. Acta 2011, 520, 1-19; DOI:10.1016/j.tca.2011.03.034.

23. Baudry, A.; Dufay, J.; Regnier, N.; Mortaigne, B. Thermal degradation and fire behaviour of unsaturated polyester with chain ends modified by dicyclopentadiene. Polym. Degrad. Stab. 1998, 61, 441-452; DOI:10.1016/S0141-3910(97)00230-9.

24. Mortaigne, B.; Bourbigot, S.; Le Bras, M.; Cordellier, G.; Baudry, A.; Dufay, J. Fire behaviour related to the thermal degradation of unsaturated polyesters. Polym. Degrad. Stab. 1999, 64, 443-448; DOI:10.1016/S0141-3910(98)00149-9.

25. Tibiletti, L.; Longuet, C.; Ferry, L.; Coutelen, P.; Mas, A.; Robin, J.-J.; Lopez-Cuesta, J.-M. Thermal degradation and fire behaviour of unsaturated polyesters filled with metallic oxides. Polym. Degrad. Stab. 2011, 96, 67-75; DOI:10.1016/j.polymdegradstab.2010.10.015.

26. Visco, A.M.; Brancato, V.; Campo, N. Degradation effects in polyester and vinyl ester resins induced by accelerated aging in seawater. J. Compos. Mater. 2011, 46, 2025-2040; DOI:10.1177/0021998311428533.

27. Mouritz, A.P.; Kootsookos, A.; Mathys, G. Stability of polyester- and vinyl ester-based composites in seawater. J. Mater. Sci. 2004, 39, 6073-6077; DOI:10.1023/B:JMSC.0000041704.71226.ee.

28. Thomason, J.L. The interface region in glass fibre-reinforced epoxy resin composites: 3 . Characterization of fibre surface coatings and the interphase. Composites 1995, 26, 487-498; DOI:10.1016/0010-4361(95)96806-H.

29. Oysaed, H.; Ruyter, I.E. Water sorption and filler characteristics of composites for use in posterior teeth. J. Dental Res. 1986, 65, 1315-1318; DOI:10.1177/00220345860650110601.

30. Feilzer, A.J.; De Gee, A.J.; Davidson, C.L. Curing contraction of composites and glass-ionomer cements. J. Prosthet. Dent.1988, 59, 297-300; DOI:10.1016/0022-3913(88)90176-x.

31. Marais, S.; Metayer, M.; Nguyen, T.Q.; Labbe, M.; Saiter, J.M. Diffusion and permeation of water through unsaturated polyester resins-influence of resin curing. Eur. Polym. J. 2000, 36, 453-462; DOI:10.1016/S0014-3057(99)00080-4. 